\title{
DECREE OF THE KING OF PRUSSIA "ON THE ELECTION OF DEPUTIES OF THE SECOND CHAMBER" OF MAY 30, 1849: THE NORMATIVE CONTENT AND IMPLEMENTATION PRACTICE
}

\author{
Yuri A. Bokov \\ Volgograd State University, Volgograd, Russian Federation
}

Introduction: an attempt is made to consider the normative regulation of the electoral relations that arose during the elections of deputies of the Prussian Landtag in 1849-1918. The purpose of the study is a comprehensive analysis of the content and practice of the implementation of Decree of the King of Prussia "On the Election of Deputies of the Second Chamber" of May 30, 1849. Results: the paper examines not only the original version of Decree of the King of Prussia of May 30, 1849, but also the texts of all the amendments that were made to this normative act. The important attention is paid to the scientific consideration of the implementation of the legal norms and their impact on the electoral behavior. Conclusions: Decree of the King of Prussia "On the Election of Deputies of the Second Chamber" of May 30, 1849 was in effect until the cancellation of Order "On Elections to the Constitutional Landtag of the Prussian State" of December 21, 1918. By the end of the XIX - beginning of the XX century, the majority of the population was actively demanding the liberalization of electoral law. The sporadic amendments did not fundamentally change the provisions of the text of the normative act. The right to vote was unequal: the voters were divided into three classes, taking into account the amount of taxes paid. The election was indirect. The regulation allowed the minority (taxpayers belonging to the first and second class), in contrast to the majority (taxpayers of the third class), to elect several times more electors. The deputies of the Landtag elected by the electors ensured the realization of the interests of the mostly wealthy citizens and minimally took into account the needs of the third-class voters. The representatives of the third class, in comparison with the first and second, participated least in the elections, since they were not motivated by the possible result, on the contrary, they were confirmed in the idea that their vote did not matter. The electoral system, based on the norms of Decree of the King of Prussia "On the Election of Deputies of the Second Chamber" of May 30, 1849, contributed to an increase in the level of absenteeism among the third-class voters.

Key words: elections, electoral and legal culture, the Landtag of Prussia, House of Representatives, class electoral system, electoral law.

Citation. Bokov Yu.A. Decree of the King of Prussia "On the Election of Deputies of the Second Chamber" of May 30, 1849: The Normative Content and Implementation Practice. Legal Concept = Pravovaya paradigma, 2021, vol. 20, no. 1, pp. 79-85. (in Russian). DOI: https://doi.org/10.15688/lc.jvolsu.2021.1.12

\section{УКАЗ КОРОЛЯ ПРУССИИ «О ПРОВЕДЕНИИ ВЫБОРОВ ДЕПУТАТОВ ВТОРОЙ ПАЛАТЫ» ОТ 30 МАЯ 1849 г.: НОРМАТИВНОЕ СОДЕРЖАНИЕ И ПРАКТИКА РЕАЛИЗАЦИИ}

\section{Юрий Александрович Боков}

Волгоградский государственный университет, г. Волгоград, Российская Федерация

Введение: в статье предпринята попытка рассмотреть нормативное регулирование избирательных отношений, возникающих при проведении выборов депутатов палаты представителей прусского ландтага в 1849-1918 годы. В качестве цели исследования определен комплексный анализ содержания и практики реали- 


\section{ТЕОРИЯ И ПРАКТИКА ГОСУДАРСТВЕННО-ПРАВОВОГО РАЗВИТИЯ}

зации Указа короля Пруссии «О проведении выборов депутатов второй палаты» от 30 мая 1849 года. Результаты: в работе исследована не только первоначальная редакция Указа короля Пруссии от 30 мая 1849 г., но и изучены тексты поправок, которые были внесены в данный нормативный акт. Важное значение уделено научному рассмотрению реализации норм права и их влияния на электоральное поведение. Выводы: Указ короля Пруссии «О проведении выборов депутатов второй палаты» от 30 мая 1849 г. действовал вплоть до отмены Распоряжением «О выборах в конституционный ландтаг Прусского государства» от 21 декабря 1918 года. К концу XIX - началу XX в. большинство населения активно выступало с требованиями либерализации избирательного права. Единичные поправки принципиально не изменяли положения текста нормативного акта. Избирательное право было неравным: первичные избиратели подразделялись на три класса с учетом уплачиваемых сумм налогов. Выборы были непрямыми. Нормативное регулирование позволяло меньшинству (налогоплательщикам первого и второго класса), в отличие от большинства (налогоплательщиков третьего класса), избирать в несколько раз большее количество выборщиков. Избранные выборщиками депутаты палаты представителей ландтага обеспечивали реализацию интересов преимущественно состоятельных граждан и минимально учитывали потребности избирателей третьего класса. Избирательная система, основанная на нормах Указа короля Пруссии «О проведении выборов депутатов второй палаты» от 30 мая 1849 г., способствовала увеличению уровня абсентеизма среди избирателей третьего класса.

Ключевые слова: выборы, электорально-правовая культура, ландтаг Пруссии, палата представителей, классовая избирательная система, избирательное право.

Цитирование. Боков Ю. А. Указ короля Пруссии «О проведении выборов депутатов второй палаты» от 30 мая 1849 г.: нормативное содержание и практика реализации // Legal Concept = Правовая парадигма. 2021. - T. 20, № 1. - C. 79-85. - DOI: https://doi.org/10.15688/lc.jvolsu.2021.1.12

В Прусском королевстве 30 мая 1849 г. был принят Указ короля Фридриха Вильгельма IV «О проведении выборов депутатов второй палаты» (далее по тексту - Указ) [21]. Указом были делиберализованы установленные в ходе революционных преобразований 1848 г. избирательные права граждан. Нормативный правовой акт с незначительными изменениями действовал вплоть до его отмены Распоряжением «О выборах в конституционный ландтаг Прусского государства» от 21 декабря 1918 года [22].

В § 1 Указа провозглашалось, что депутаты второй палаты ландтага - палаты представителей (депутатов) Пруссии (Abgeordnetenhaus) - избираются в избирательных округах выборщиками, а выборщики, в свою очередь, избираются первичными избирателями (Die Urwähler) в первичных избирательных округах.

Данной нормой права был закреплен принцип косвенного избирательного права. Ранее принятый Вторым Соединенным ландтагом Пруссии избирательный закон от 8 апреля 1848 г. содержал аналогичную норму [23]. Обосновывая необходимость установления именно непрямых выборов, сторонники правительства отмечали, что обусловлено это недостаточным уровнем культуры народа.
Палата представителей состояла из 350 депутатов (§ 2). Количество избираемых в каждом административном округе депутатов было указано в приложении к Указу. Первые изменения были внесены в данный параграф и приложение «Временным избирательным законом для выборов второй палаты княжества Гогенцоллерн» от 30 апреля 1851 года [13]. Немецкие княжества Гогенцоллерн-Гехингенское и Гогенцоллерн-Зигмарингенское по договору 1849 г. вошли в состав Пруссии, в связи с чем возникла необходимость соответствующего правового регулирования избирательных отношений. Княжества Гогенцоллерны делились на два избирательных округа, в каждом избирался один депутат палаты представителей ландтага Пруссии.

Законом «Об установлении избирательных округов для палаты депутатов» от 27 июня 1860 г. [12] параграф второй был изменен. Теперь устанавливалось, что избирательные округа, места выборов и число представителей, которые должны быть избраны в каждом округе в палату представителей, определяются в соответствии с содержанием прилагаемого к Указу списка. В тех избирательных округах, в которых в списке были названы два места для голосования, выборы происходили первыми в первом названном месте, а вторыми - во втором, и таким образом продолжа- 
лись в таком же порядке поочередно. В избирательном округе Шлейзинген-Цигенрюк (№ 5, административный округ Эрфурт) выборы проводились по следующему порядку: дважды подряд в Шлейзингене, а затем в третий раз в Ранисе. Принятие данной нормы должно было показать учет интересов всех провинций Пруссии. На практике указанная система смены места голосования не способствовала увеличению явки избирателей, так как приходилось для выражения своей позиции порой преодолевать значительные расстояния.

Формирование избирательных округов должно было осуществляться правительствами в соответствии с численностью населения, определенной последней всеобщей переписью. Округа, принадлежащие к разным местностям, могли быть (в виде исключения) объединены обер-президентом в один избирательный округ, если это представлялось необходимым с учетом ситуации и других обстоятельств (§ 3). Законом от 27 июня 1860 г. [12] $\S 3$ Указа был дополнен положением о том, что министр внутренних дел может отклониться от правила, предусмотренного в $\S 2$. Министр внутренних дел в том случае, если проведение выборов в месте, указанном в списке соответствующего избирательного округа, становилось невозможным из-за инфекционных заболеваний или других непредотвратимых обстоятельств, наделялся правом изменить место голосования. Другое место проведения выборов, назначаемое министром внутренних дел, не должно было находиться за пределами округа.

Один выборщик избирался на каждые полные 250 жителей (§ 4). Муниципалитеты численностью менее 750 человек должны были объединяться администратором округа с одним или несколькими соседними муниципалитетами для образования первичного избирательного округа (§ 5). Законом от 30 апреля 1851 г. данное положение было уточнено указанием, что в первичных избирательных округах, которые состоят из нескольких муниципалитетов, можно не проводить избирательное собрание для всего округа, а также можно было запланировать избирательные собрания для части одного и того же муниципалитета или для каждого отдельного муниципалитета [13]. Муниципалитеты с населением от 1750 жителей требовалось делить на несколько первичных избирательных округов. Они должны были организовываться таким образом, чтобы можно было избрать максимум 6 выборщиков (§ 6). Первичные избирательные округа по возможности нужно было сформировать так, чтобы число избирателей, подлежащих избранию в каждом из них, делилось на три (§ 6). Следовательно, численность первичного избирательного округа определялась пределами от 750 до 1749 жителей, которыми избиралось от 3 до 6 выборщиков.

Используя несложные математические расчеты, можно установить, что принцип равенства голосов избирателей при избрании выборщиков мог существенно искажаться используемой избирательной географией. В округе численностью 1749 человек один выборщик фактически избирался не на 250 жителей, а на 291 жителя. Расхождение составляло в таком случае около 16,5 \%. Еще больший разрыв виден в случае, если численность избирательного округа была чуть менее 1000 жителей. Один выборщик мог избираться на 333 жителя, и тогда расхождение составляло около $33,2 \%$.

Активным избирательным правом по избранию выборщиков наделялись все самостоятельные подданные Пруссии, достигшие 24летнего возраста, постоянно проживающие не менее шести месяцев на территории соответствующего муниципалитета, не утратившие гражданских прав на основании судебного решения и не получающие помощи из общественных средств призрения (§ 8). В Указе использовалось слово «пруссак», которое трактовалось применительно к избирательному праву исключительно как лицо мужского пола.

Военнослужащие постоянной армии и регулярных частей ландвера должны были голосовать по месту своего нахождения, независимо от того, как долго они находились там до выборов. Если их количество было более 750 человек, то они образовывали один или несколько специальных избирательных округов. Призывникам ландвера, призванным на военную службу во время выборов, надлежало голосовать в своем округе по месту своего пребывания (§ 9).

Первичные избиратели делились на три отдела, части (Abteilung) в соответствии с 
суммами прямых государственных налогов, подлежащих уплате ими: налог на класс, налог на имущество, налог на торговлю (§ 10). Законом «О подоходном налоге» от 24 июня 1891 г. классовый налог и классифицированный подоходный налог были заменены единым подоходным налогом [9]. В связи с этим законами «Об изменении избирательной процедуры» от 24 июня 1891 г. [11] и от 29 июня 1893 г. [10] перечень учитываемых налогов был расширен.

Выражение «класс избирателей» (Wählerklasse) нормативно не закреплялось, но получило широкое распространение в качестве неофициального. Печать, в том числе правительственная, также активно публиковала статьи, в которых использовала для характеристики избирательной системы Пруссии это выражение $[6 ; 15 ; 16]$. Выпускались агитационные статьи, адресованные избирателям отдельных классов [14], выделялись привилегированные классы [18]. Использование понятия «класс» применительно к избирателям было преимущественно обусловлено наличием классового налога, служившего первоначальной основой для распределения на отделы первичных избирателей.

Первый отдел состоял из тех первичных избирателей, которые платили самые высокие суммы налогов, составлявшие до трети всех налогов. Второй отдел образовывали те первичные избиратели, которые выплачивали следующую треть всех налогов, состоящую из более низких сумм. В третий отдел включались остальные первичные избиратели, облагаемые самым низким налогом, а также не платившие налогов.

Каждый отдел избирал третью часть выборщиков. В тех случаях, когда число выборщиков, подлежащих избранию, без остатка не делилось на три, то руководствовались следующим правилом: в случае, если остался только один выборщик, он избирается первичными избирателями второго отдела; осталось два - один избирается в первом отделе, другой - в третьем (§ 14).

Так как местные налоги в Пруссии были чрезвычайно разными, то условия для отнесения к соответствующему отделу были очень различны в зависимости от провинции. Средняя налоговая производительность Берлинско- го избирателя во втором отделе на выборах в палату депутатов ландтага в 1898 г. составляла 445 марок, а соответствующего избирателя в округе Гогенцоллерн - 24 марки [20, S. 183]. Не было равенства политической власти и лиц, уплачивающих одинаковые налоги [2, с. 165], так как в каждом избирательном округе определялась индивидуальная сумма уплачиваемых налогов, необходимая для зачисления к определенному классу. Во Франкфурте-на-Майне на выборах 1903 г. 3 \% избирателей имели право голосовать в первом классе, $12 \%$ - во втором и $85 \%$ - в третьем [5].

Избирательная система, созданная на основании Указа, значительной частью населения воспринималась как самая жалкая из всех избирательных систем [3]. Высказывалось мнение, что если бы изобретатели этой системы знали ее низкую эффективность, то они бы ее не внедрили [8]. Неприкасаемое политическое доминирование богатых аграриев, юнкеров и консерваторов представляло собой величайшее препятствие на пути демократических реформ в интересах большинства населения [7]. Поверенный Российской империи в Берлине в рапорте от 16/29 мая 1913 г. на имя министра иностранных дел С.Д. Сазонова указывал, что вопросы, связанные с выборным правом в Пруссии, являются наиболее жгучими в здешней политической жизни [4].

\section{Выводы}

Классовое избирательное право использовалось в истории нескольких государств, но самым известным и ярким примером выступает трехклассное избирательное право, установленное Указом короля Пруссии «О проведении выборов депутатов второй палаты» от 30 мая 1849 года. Оно использовалось для избрания палаты депутатов прусского ландтага с 1849 г. до падения монархической формы правления в 1918 году.

Название связано с тем, что избиратели градуировались с учетом налоговой платежеспособности на три отдела. Нормативно использовалось понятие «отдел», но в общественной жизни укоренилось «класс». Это было всеобщее мужское и неравное избирательное право. Голоса первичных избирателей имели очень 
различное значение в зависимости от класса, территории, особенностей образования избирательных округов. Прусское трехклассное избирательное право стало ненавистным символом дефицита демократических идей в Пруссии. Этот дефицит имел последствия для всей Германии, потому что Пруссия была доминирующей державой.

Основная идея, находящаяся в основе прусской трехклассной избирательной системы, заключалась в следующем: граждане, вносящие финансово наибольший вклад в государство через свои налоги, соответственно получают больше политических прав на участие, в отличие от тех, которые живут только за государственный счет и, следовательно, за деньги других людей. Прусская трехклассная избирательная система была призвана установить за богатыми юнкерами, представляющими меньшинство населения, практически полную монополию на принятие законов. Расширение избирательных прав означало бы изменение существующего положения, при котором богатые избиратели пользовались благосклонностью трехклассной системы. Представители третьего класca, в сравнении с первым и вторым, менее всех участвовали в выборах, так как не были мотивированы возможным результатом, они, наоборот, утверждались в мысли, что их голос не имеет значения.

Потомки ставят прусскому трехклассному избирательному праву более мягкую оценку, в отличие от его современников. Хедвиг Рихтер указывал, что прусскую попытку снять социальную напряженность, вызванную современностью, с помощью трехклассного избирательного права вряд ли можно назвать безуспешной [19, S. 253]. В Великобритании, Швеции или Нидерландах до Первой мировой войны из-за цензурного избирательного права многим мужчинам вообще не разрешалось выбирать, в то время как в Пруссии каждый взрослый мужчина имел хотя бы минимально решающий голос. Всеобщее мужское избирательное право существовало за пределами Германии до начала XIX в. только в Швейцарии и Франции. В Швеции, примерно около 1900 г., из-за явно высокого ценза было разрешено голосовать только $8,2 \%$ от общей численности населения [17, S. 134]. По нашим подсчетам, при трехклассной избирательной системе около $18 \%$ населения были наделены активным избирательным правом на выборах палаты представителей. Важно также отметить, что на основании Указа было предложено такое народное представительство, при котором народу передавались лишь ограниченные права [1, с. 101].

\section{СПИСОК ЛИТЕРАТУРЫ}

1. Боков, Ю. А. Зарождение избирательных прав пруссаков (19 ноября 1808 - 30 мая 1849 года) / Ю. А. Боков // Вестник Волгоградского государственного университета. Серия 5, Юриспруденция. -2012 . - № 2 (17). - С. 99-105.

2. Боков, Ю. А. Прусская трехклассная избирательная система (1849-1918 гг.) // Власть. - 2009. № 10. - C. 163-165.

3. Объявление о собрании // РГАСПИ. Ф. 215. - Оп. 1. - Д. 271. - Л. 329.

4. Рапорт С.Д. Сазонова // АВПРИ. - Ф. 133.Оп. 470. - Д. 36. - Л. 6.

5. An die Landtags-Wähler 08. Juni 1908 des Wahlkreises Frankfurt a. М. // РГАСПИ. - Ф. 215. Оп. 1. - Д. 171.

6. Aus dem Reiche // Teltower Kreisblatt. 1893. -28. Oktober. - S. 2.

7. Bericht zur Sitzung im Abgeordnetenhaus //Lübecker Volksboten. - 1914. - 19. Mai. - S. 1-2.

8. Der Reichstag und die Wahlen // ProvinzialCorrespondenz. - 1867.-03. April. - S. 3 .

9. Einkommensteuergesetz vom 24. Juni 1891 // Gesetz-Sammlung für die Königlichen Preußischen Staaten. - 1891. - S. $175 \mathrm{ff}$.

10. Gesetz, betreffend Änderung des Wahlverfahrens vom 29. Juni 1893 // Gesetz-Sammlung für die Königlichen Preußischen Staaten. - 1893. - S. 103 ff.

11. Gesetz, betreffend Änderung des Wahlverfahrens, vom 24. Juni 1891. // GesetzSammlung für die Königlichen Preußischen Staaten. - 1891.

12. Gesetz, die Feststellung der Wahlbezirke für das Haus der Abgeordneten betreffend, vom 27. Juni 1860 // Gesetz-Sammlung für die Königlichen Preußischen Staaten. - 1860. - S. 357 ff.

13. Interimistisches Wahlgesetz für die Wahlen zur Zweiten Kammer in den Fürstenthümern Hohenzollern vom 30. April $1851 / /$ Gesetz-Sammlung für die Königlichen Preußischen Staaten. - 1851. - S. 216 ff.

14. Mitbürger! Wähler der 3. Classe! // Kölner Stadt-Anzeiger. - 1881. - 7. November. - S. 1.

15. Nachrichten aus dem Kreise und der Provinz // Teltower Kreisblatt. - 1896. - 15. März. -S. 2. 
16. Neues zur Klassensteuer // Neueste Mitteilungen. - 1882. - 03. Juli. S. 2.

17. Poensgen, O. Das Wahlrecht / O. Poensgen. Leipzig: Teubner, 1909.

18. Preußen und das Wahlrecht // Tabakarbeiter. 1910. - 20. Febr. - № 8. - S. 2.

19. Richter, H. Moderne Wahlen. Eine Geschichte der Demokratie in Preußen und den USA im 19. Jahrhundert / H. Richter. - Hamburg : Hamburger Edition, 2017.

20. Ritter, G. Wahlgeschichtliches Arbeitsbuch: Materialien zur Statistik des Kaiserreichs 18711918. Zweites Kapitel: Preußen / G. Ritter. - München : Verlag C. H. Beck, 1980.

21. Verordnung über die Ausführung der Wahl der Abgeordneten zur Zweiten Kammer vom 30. Mai 1849 // Gesetz-Sammlung für die Königlichen Preußischen Staaten. - 1850. - S. $205 \mathrm{ff}$.

22. Verordnung über die Wahlen zur verfassunggebenden preußischen Landesversammlung vom 21. Dezember 1918 // Gesetz-Sammlung für die Königlichen Preußischen Staaten. - 1918. - S. 201 ff.

23. Wahlgesetz für die zur Vereinbarung der preußischen Staatsverfassung zu berufende Versammlung unter dem 8. April 1848 // GesetzSammlung für die Königlichen Preußischen Staaten. 1848. - S. $89 \mathrm{ff}$.

\section{REFERENCES}

1. Bokov Yu.A. Zarozhdenie izbiratel'nyh prav prussakov (19 noyabrya 1808 - 30 maya 1849 goda). Vestnik Volgogradskogo gosudarstvennogo universiteta. Seriya 5, Yurisprudentsiya, 2012, no. 2 (17), pp. 99-105.

2. Bokov Yu.A. Prusskaya tryohklassnaya izbiratel'naya sistema (1849-1918 gg.). Vlast', 2009, no. 10 , pp. 163-165.

3. Obyavlenie o sobranii. RGASPI, f. 215, op. 1 , d. $271,1.329$.

4. Raport S. D. Sazonova. AVPRI, f. 133, op. 470, d. $36,1.6$

5. An die Landtags-Waehler 08. Juni 1908 des Wahlkreises Frankfurta. M. RGASPI, f. 215, op. 1, d. 171.

6. Aus dem Reiche. Teltower Kreisblatt, 1893, 28. Oktober, S. 2.

7. Bericht zur Sitzung im Abgeordnetenhaus. Luebecker Volksboten, 1914, 19. Mai, S. 1-2.

8. Der Reichstag und die Wahlen. ProvinzialCorrespondenz, 1867, 03. April, S. 3.
9. Einkommensteuergesetz vom 24. Juni 1891. Gesetz-Sammlung fuer die Koeniglichen Preussischen Staaten, 1891, S. $175 \mathrm{ff}$.

10. Gesetz, betreffend Aenderung des Wahlverfahrens vom 29. Juni 1893. Gesetz-Sammlung für die Koeniglichen Preussischen Staaten, 1893, S. 103 ff.

11. Gesetz, betreffend Aenderung des Wahlverfahrens, vom 24. Juni 1891. GesetzSammlung für die Koeniglichen Preussischen Staaten, 1891.

12. Gesetz, die Feststellung der Wahlbezirke für das Haus der Abgeordneten betreffend, vom 27. Juni 1860. Gesetz-Sammlung für die Koeniglichen Preussischen Staaten, 1860, S. 357 ff.

13. Interimistisches Wahlgesetz für die Wahlen zur Zweiten Kammer in den Fuerstenthuemern Hohenzollern vom 30. April 1851 // Gesetz-Sammlung für die Koeniglichen Preussischen Staaten, 1851, S. $216 \mathrm{ff}$.

14. Mitbuerger! Wähler der 3. Classe! Koelner Stadt-Anzeiger, 1881, 7. November, S. 1.

15. Nachrichten aus dem Kreise und der Provinz. Teltower Kreisblatt, 1896, 15. März, S. 2.

16. Neues zur Klassensteuer. Neueste Mitteilungen, 1882, 03. Juli, S. 2.

17. Poensgen O. Das Wahlrecht. Leipzig, Teubner, 1909.

18. Preußen und das Wahlrecht. Tabakarbeiter, 1910, 20. Febr., no. 8, S. 2.

19. Richter H. Moderne Wahlen. Eine Geschichte der Demokratie in Preußen und den USA im 19. Jahrhundert. Hamburg, Hamburger Edition, 2017.

20. Ritter G. Wahlgeschichtliches Arbeitsbuch: Materialien zur Statistik des Kaiserreichs 18711918. Zweites Kapitel: Preußen. Muenchen, Verlag C. H. Beck, 1980.

21. Verordnung über die Ausführung der Wahl der Abgeordneten zur Zweiten Kammer vom 30. Mai 1849. Gesetz-Sammlung für die Königlichen Preussischen Staaten, 1850, S. 205 ff.

22. Verordnung über die Wahlen zur verfassunggebenden preußischen Landesversammlung vom 21. Dezember 1918. Gesetz-Sammlung für die Koeniglichen Preussischen Staaten, 1918, S. $201 \mathrm{ff}$.

23. Wahlgesetz für die zur Vereinbarung der preussischen Staatsverfassung $\mathrm{zu}$ berufende Versammlung unter dem 8. April 1848. GesetzSammlung fuer die Koeniglichen Preussischen Staaten, 1848, S. $89 \mathrm{ff}$. 
Ю.А. Боков. Указ короля Пруссии «О проведении выборов депутатов второй палаты» от 30 мая 1849 г.

\section{Information About the Author}

Yuri A. Bokov, Candidate of Sciences (Jurisprudence), Associate Professor, Department of Constitutional and Municipal Law, Volgograd State University, Prosp. Universitetsky, 100, 400062 Volgograd, Russian Federation, bokov2004@yandex.ru, bokov@volsu.ru, https://orcid.org/0000-0001-6357-9599

\section{Информация об авторе}

Юрий Александрович Боков, кандидат юридических наук, доцент кафедры конституционного и муниципального права, Волгоградский государственный университет, просп. Университетский, 100, 400062 г. Волгоград, Российская Федерация, bokov2004@yandex.ru, bokov@volsu.ru, https://orcid.org/0000-0001-6357-9599 